\title{
Biodiversity of Duckweeds in Eastern China and Their Potential for Bioremediation of Municipal and Industrial Wastewater
}

\author{
Yuzhen Zhou*, Guimin Chen, Anton Peterson, Xiaomeng Zha, Jingwen Cheng, Sijia Li, \\ Dandan Cui, Haotian Zhu, Olena Kishchenko, Nikolai Borisjuk"
}

Jiangsu Collaborative Innovation Center of Regional Modern Agriculture \& Environmental Protection, The School of Life Science, Huaiyin Normal University, Huaian, China

Email: ${ }^{\star}$ zyz@hytc.edu.cn, ${ }^{\sharp}$ nborisjuk@hytc.edu.cn

How to cite this paper: Zhou, Y.Z., Chen, G.M., Peterson, A., Zha, X.M., Cheng, J.W., Li, S.J., Cui, D.D., Zhu, H.T., Kishchenko, O. and Borisjuk, N. (2018) Biodiversity of Duckweeds in Eastern China and Their Potential for Bioremediation of Municipal and Industrial Wastewater. Journal of Geoscience and Environment Protection, 6, 108-116.

https://doi.org/10.4236/gep.2018.63010

Received: December 27, 2017

Accepted: April 5, 2018

Published: April 8, 2018

\begin{abstract}
Duckweed is a group of aquatic plants with the potential of wastewater remediation and fast accumulation of biomass. The accumulated biomass, rich in cellulose, starch and protein, can be used for biofuel, bio-fertilizer, animal feed and human food. Characterization of natural biodiversity of duckweed species is essential for the germplasm preservation and various practical applications. We have collected samples of duckweed in eastern China and characterized species biodiversity by genotyping, using chloroplast (atpF-atpH and psbK-psbI spacers). Spirodela polyrhiza was revealed as a clear dominant duckweed species in all locations of the area. Other duckweed species were identified as Landoltia punctata, Lemna aequinoctialis and Lemna turionifera. Selected isolates of these four species were used in the experiments to estimate their potential in removing nitrogen and phosphorus nutrients from municipal and industrial wastewater sampled at the local sewage plants. Duckweed was able to reduce the concentration of nitrogen up to $98 \%$ and phosphorus up to $96 \%$. The presented data demonstrates high efficiency of the local duckweed isolates for bioremediation of different types of wastewater and the great potential of duckweed for wastewater treatment when incorporated into the purification chain.
\end{abstract}

\section{Keywords}

Duckweed Biodiversity, Municipal Wastewater, Industrial Wastewater, Water Remediation, Nitrogen, Phosphorus 


\section{Introduction}

Water supply is one of the most serious challenges faced by the world today. In many Asian countries and elsewhere, the demand for potable water doubles every 10 - 15 years due to both the rising domestic consumption and the increasing needs of industry [1] [2]. Eutrophication of water resource is a global concern and has been identified as a major environmental problem for water resource management. Excess agrochemical fertilizers, primarily nitrogen $(\mathrm{N})$ and phosphorus $(\mathrm{P})$, are the major cause of eutrophication in waterbodies worldwide. In China, application of chemical fertilizers amounts to around a third of the world's total usage. According to www.statista.com, the use of chemical fertilizers in the world in 2014 was 186.7 million metric tons, and in China it was 59.96 million metric tons, with Chinese farmers applying 70 percent more chemicals to crops compared to the world average (China's Ministry of Agriculture). Another source of water pollutants are nutrients used in the fast growing aquaculture systems. The main contaminants of the aquaculture wastewater effluent are ammonium, organic $\mathrm{N}$ and $\mathrm{P}$ [3]. Only about $15 \% \mathrm{~N}$ and $25 \%$ Pof the aquaculture feed are assimilated by fish and shrimps, while the unutilized part accumulates in the water or in the sediment [4]. The eutrophication of water bodies due to aquaculture wastewater is on a sharp rise during the last 20 years, at a rate of $2 \%$ - 4\% per year in the Yangtze River basin and Zhujiang Delta basin [4].

The need to reduce anthropogenic nutrients in aquatic ecosystems for preventing water eutrophication has been widely recognized [5]. A number of physical, chemical, and biological methods used in wastewater treatment are applied in freshwater pond aquaculture systems. Among them biological treatment has been considered the most feasible approach for enabling water reuse. As an eco-friendly method, cultivation of aquatic macrophytes is attractive for nutrient removal and the restoration of eutrophic waterbodies [6].

Duckweed has been considered for phytoremediation of eutrophic water due to a number of its specific features: 1) excellent capacity for nutrient uptake [7]; 2) fast growth rate and high biomass production; 3) resistance to pollution and comparatively cold tolerant; 4) wide distribution in natural aquatic ecosystems [8]; 5) easy removal from water. As an additional benefit, the produced biomass with high content of protein and starch, can be used for the production of animal feeds, fertilizer, and bioenergy products [9] [10]. Thus, duckweed has become an attractive solution for recycling of nutrients from wastewater system [11].

In this study, we collected samples of duckweeds in eastern China, identified the species by genotyping, and used selected isolates ecotypes in experiments to remediate industrial and municipal wastewater sampled at the local sewage plants.

\section{Materials and Methods}

\subsection{Plant Material and Growth Condition}

Four duckweed species used in this study were collected at different locations in 
eastern China. The identity of the collected duckweed ecotypes was determined by DNA barcoding using primers specific for chloroplast intergenic spacersatpF-atpH (ATP) and psbK-psbL (PSB) as previously described [12]. Following species identification by barcoding, duckweed fronds were surface sterilized in solution containing $0.5 \%$ of sodium hypochlorite solution and $0.1 \%$ benzalkonium bromide and washed with autoclaved water. The procedure was repeated in 2 days and fronds were put on solid agar medium supplemented with SH salts [13].

\subsection{Sample Handling and Experiment Design}

To generate duckweed biomass for wastewater treatment, four duckweed species were grown under aseptic condition in $500 \mathrm{~mL}$ flasks containing $200 \mathrm{~mL}$ liquid $\mathrm{SH}$ medium with $5 \mathrm{~g} / \mathrm{L}$ sucrose. The plants were cultivated for about two weeks in incubator at $23^{\circ} \mathrm{C} \pm 1{ }^{\circ} \mathrm{C}$ with a photon flux density of $50-60 \mu \mathrm{mol} \cdot \mathrm{m}^{-2} \mathrm{~s}^{-1}$ provided by cool white fluorescent bulbs in a $16 \mathrm{~h}$ light $/ 8 \mathrm{~h}$ dark cycle. Before inoculation into wastewater, the duckweed fronds were collected, washed thoroughly with distilled water and blotted with filter paper. The fronds were weighted, and $2 \mathrm{~g}$ of the plant material was either inoculated in plastic basins filled with $200 \mathrm{ml}$ of wastewater, filtered with medium speed filter paper, or put in a thermostat to dry out for 2 days at $85^{\circ} \mathrm{C}$ for dry weight determination. The municipal and industrial wastewater samples (influent and effluent) were collected from Huaian local municipal sewage plant $(33.629349,119.044762)$ and industrial sewage plant (N 33.381293, E 118.993329), respectively. All tests were conducted in four repeats for each condition. The distilled water was added every 2 days to each container to keep stable water level. Water samples were taken at different time points to check the total nitrogen (TN) and total phosphorus (TP) concentrations. At the end of the experiment, duckweeds were collected, washed with distilled water, and checked for their dry weight as mentioned above.

\subsection{Measurement of TP and TN Concentrations}

TP concentration (TP, $\mathrm{mg} / \mathrm{L}$ ) was measured using the ammonium molybdatespectrophometric method, used for monitoring and analyzing water and wastewater in China. TN concentration $(\mathrm{TN}, \mathrm{mg} / \mathrm{L})$ was determined using standard alkaline potassium persulfate digestion followed by UV spectrophotometry.

\section{Results}

\subsection{The Identity of the Duckweed Strains}

Four duckweed species used in the experiments were collected at different locations in eastern China (Figure 1). The species identity was determined by DNA genotyping using dual chloroplast DNA barcodes atpF-atpH (ATP) and psbK-psbL (PSB). Chloroplast DNA fragments, amplified by PCR, were directly sequenced using one of the amplification primers and blasted against the 


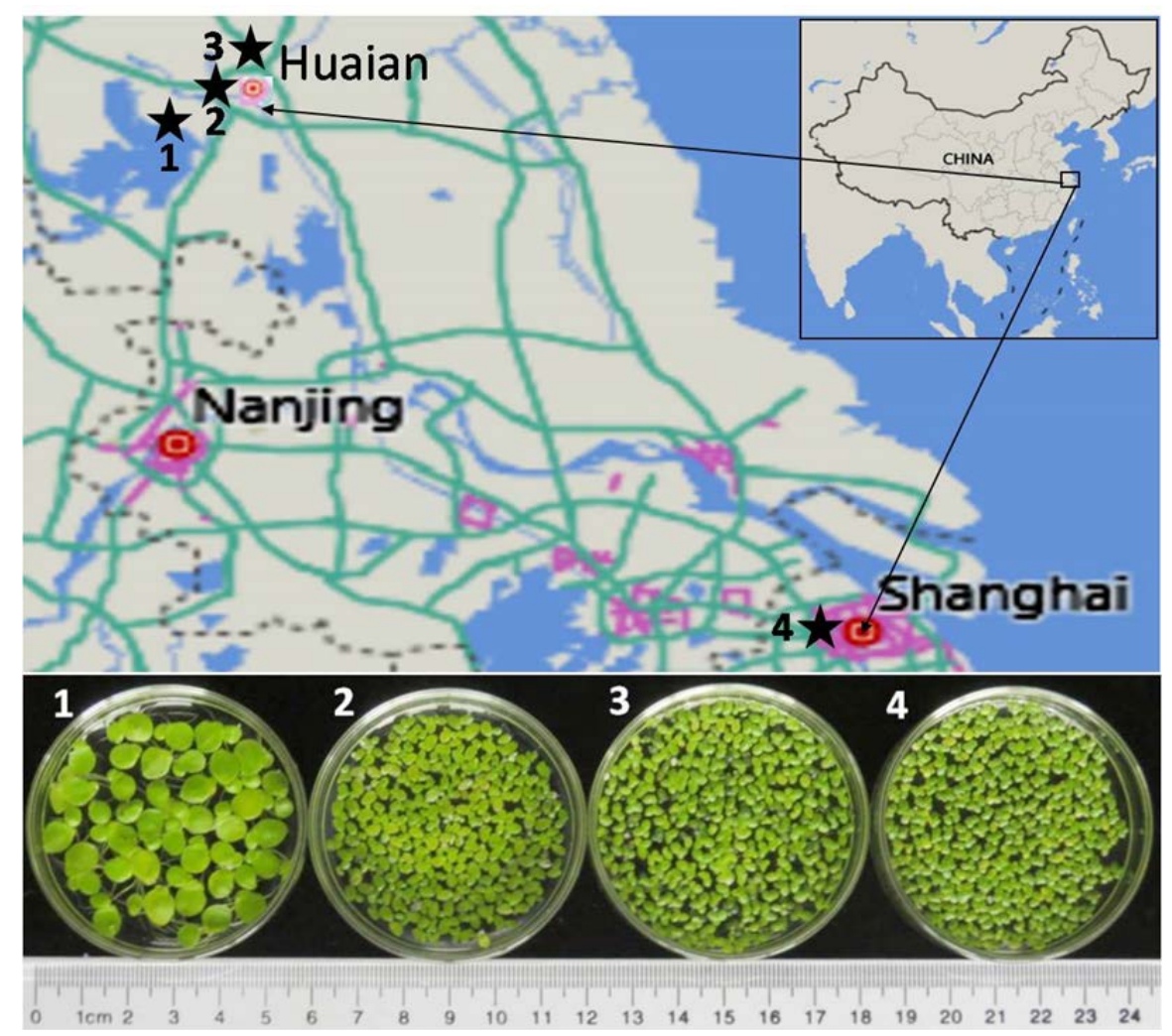

Figure 1. A map with locations of sample collection and images of duckweed species used in the study. 1: Spirodela polyrhiza (N 33"17'40; E 118"49'45); 2: Lemna turionifera (N 33"618817, E 119"001941); 3: Landoltia punctata (N 33"599292, E 119"05674); 4: Lemna aequinoctialis (N 31"14'20; E 121"28'40).

sequences available in the NCBI DNA database. The combination of ATP and PSB chloroplast barcodes [12] clearly identified three out of four species as, Spirodela polyrhiza, Landoltia punctata, and Lemna turionifera. For the fourth sample, collected from the lake at People's square park in Shanghai, the sequence alignment revealed Lemna aequinoctialis as the species with highest Blast score for ATP barcode and L. turionifera with the highest score for PSB. Therefore, in this case we have used a third chloroplast DNA barcode, RpoB [14], which clearly identified the species as L. aequinoctialis.

\subsection{Bioremediation of Municipal Wastewater}

To test the ability of duckweed to accumulate nutrients, mainly $\mathrm{N}$ and $\mathrm{P}$, from local municipal wastewater, four duckweed species ( $L$. aequinoctialis, $S$. polyrhi$z a, L$. punctata and L. turionefera) were used to treat influent and effluent of the local municipal wastewater treatment plant for 3 weeks. For determination of TN and TP concentrations, water samples were taken at the $3^{\text {rd }}, 7^{\text {th }}$, and $15^{\text {th }}$ days after duckweed inoculation. As shown in Figure 2, the original concentrations of TN in influent and effluent water from local municipal sewage plant, after filtering, are $21 \mathrm{mg} / \mathrm{L}$ and $11 \mathrm{mg} / \mathrm{L}$, respectively. In 3 days cultivation, duckweed quickly lowered the TN concentration, with the much steeper $\mathrm{N}$ decrease in the influent 

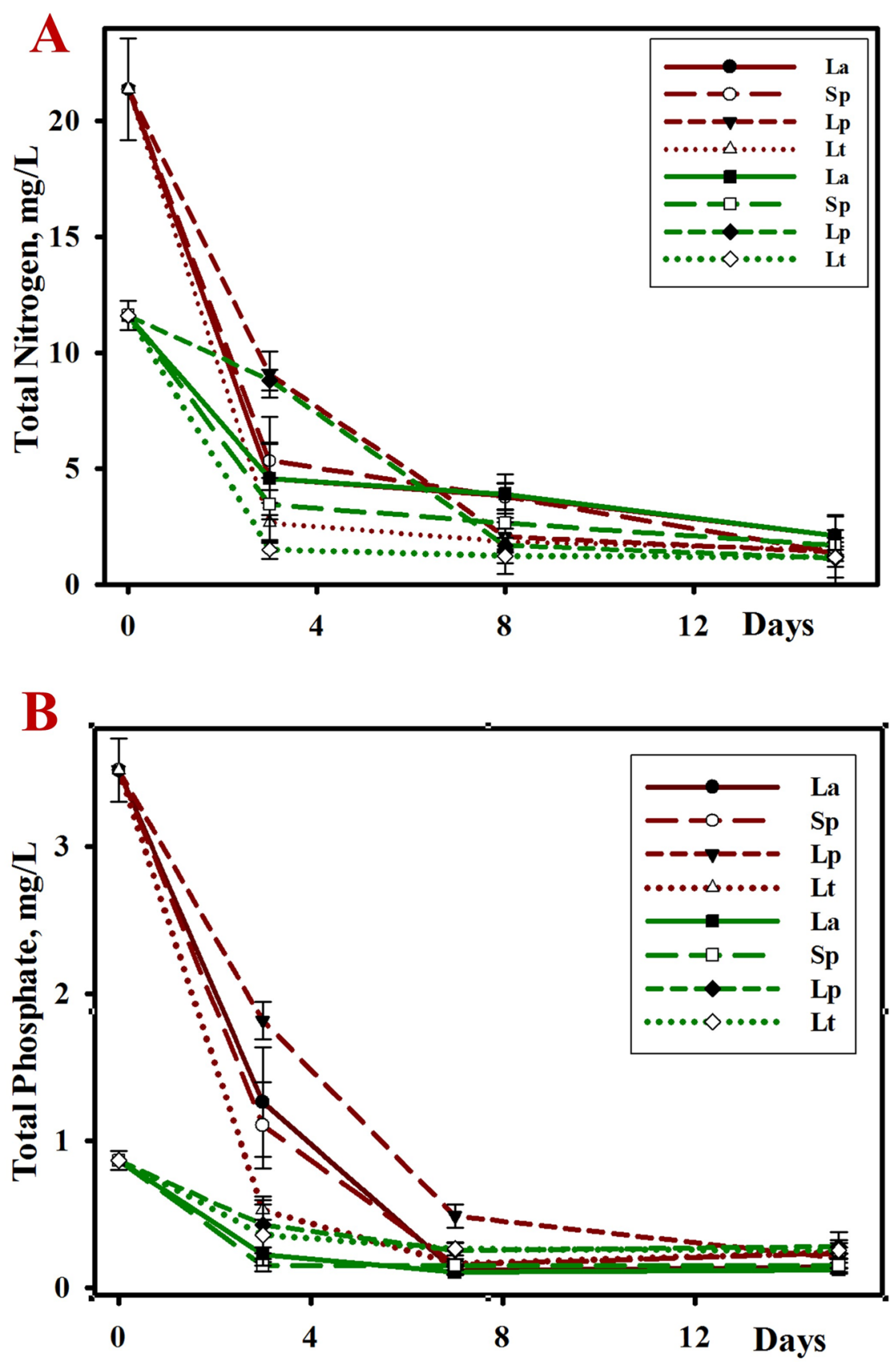

Figure 2. Removal of $\mathrm{N}(\mathrm{A})$ and $\mathrm{P}(\mathrm{B})$ from municipal wastewater by four duckweed species. Red lines refer to duckweeds cultivated in influent waistwater, and the green lines refer to to duckweeds cultivated in effluent wastewater. La: $L$. aequinoctialis; Sp: S. polyrhiza; Lp: L. punctata; Lt: L. turionefera.

water compared to the effluent. For influent water, the TN concentration is lower than that of the effluent from sewage plant for all four duckweed species, with L. turionefera demonstrating the fastest removal rate. After 15 days' treatment, the TN was removed more than $90 \%$ for both influent and effluent water (Table 1), with final total concentration being around $1 \mathrm{mg} / \mathrm{L}$ or below. This $\mathrm{N}$ concentration is much lower than the National standard for treated wastewater 
Table 1. Concentrations of TN and TP in municipal and industrial wastewater samples and the nutrients removal rate by four duckweed species.

\begin{tabular}{|c|c|c|c|c|c|c|c|c|c|}
\hline & & $\begin{array}{c}\text { Starting } \\
\text { TN, mg/L }\end{array}$ & $\begin{array}{c}\text { Final TN, } \\
\mathrm{mg} / \mathrm{L}\end{array}$ & $\begin{array}{c}\text { Net } \mathrm{N} \text { taken, } \\
\mathrm{mg} / \mathrm{L}\end{array}$ & $\begin{array}{c}\mathrm{N} \\
\text { removal \% }\end{array}$ & $\begin{array}{l}\text { Starting TP, } \\
\mathrm{mg} / \mathrm{L}\end{array}$ & $\begin{array}{c}\text { Final TP, } \\
\mathrm{mg} / \mathrm{L}\end{array}$ & $\begin{array}{c}\text { Net } \mathrm{P} \text { taken, } \\
\mathrm{mg} / \mathrm{L}\end{array}$ & $\begin{array}{c}\mathrm{P} \\
\text { removal \% }\end{array}$ \\
\hline \multirow{3}{*}{$\mathrm{La}$} & $\mathrm{IM}$ & 21.4 & 1.2 & 20.2 & 94.4 & 3.5 & 0.1 & 3.4 & 95.9 \\
\hline & EM & 11.6 & 0.7 & 10.9 & 93.8 & 0.9 & 0.1 & 0.7 & 85.6 \\
\hline & II & 74.9 & 12.3 & 62.6 & 83.6 & 0.8 & 0.2 & 0.6 & 73.8 \\
\hline \multirow{3}{*}{ Sp } & $\mathrm{IM}$ & 21.4 & 0.4 & 21.0 & 98.1 & 3.5 & 0.2 & 3.3 & 93.3 \\
\hline & EM & 11.6 & 0.9 & 10.7 & 91.9 & 0.9 & 0.2 & 0.7 & 82.5 \\
\hline & II & 74.9 & 12.0 & 62.9 & 84.0 & 0.8 & 0.2 & 0.6 & 75.0 \\
\hline \multirow{3}{*}{ Lp } & $\mathrm{IM}$ & 21.4 & 1.2 & 20.2 & 94.2 & 3.5 & 0.2 & 3.3 & 94.3 \\
\hline & EM & 11.6 & 0.3 & 11.3 & 97.4 & 0.9 & 0.3 & 0.6 & 67.5 \\
\hline & II & 74.9 & 6.1 & 68.8 & 91.9 & 0.8 & 0.2 & 0.5 & 72.1 \\
\hline \multirow{3}{*}{$\mathrm{Lt}$} & $\mathrm{IM}$ & 21.4 & 0.4 & 21.0 & 98.2 & 3.5 & 0.2 & 3.3 & 93.1 \\
\hline & $\mathrm{EM}$ & 11.6 & 1.1 & 10.5 & 90.3 & 0.9 & 0.3 & 0.6 & 70.6 \\
\hline & II & 74.9 & 2.7 & 72.1 & 96.3 & 0.8 & 0.2 & 0.5 & 70.9 \\
\hline
\end{tabular}

IM: influent water from local municipal sewage plant; EM: effluent water from local municipal sewage plant; II: influent water from local industrial sewage plant.

(15 mg/L, China Standard GB 18918-2002), and close to the $\mathrm{N}$ level accepted for drinking water (1.5 mg/L, China Standard GB3838-2002).

The TP concentrations in influent and effluent water from local municipal sewage plant were $3.5 \mathrm{mg} / \mathrm{L}$ and $0.87 \mathrm{mg} / \mathrm{L}$, respectively. As for $\mathrm{N}$ removal, the TP concentration drops quickly for the first three days of duckweed cultivation for all duckweed species. During the 15 days treatment, up to $93 \%$ of the TP was removed from the influent wastewater and $70 \%-85 \%$ from the effluent water.

\subsection{Bioremediation of Industrial Wastewater}

Composition of the influent wastewater treated by the local industrial water purification station significantly differs from the municipal wastewater in terms of $\mathrm{N}$ and $\mathrm{P}$ concentrations. As shown in Figure 3, the TN concentration in industrial wastewater $(74.9 \mathrm{mg} / \mathrm{L})$ is around 3.5 times higher than that of the local municipal wastewater $(21.4 \mathrm{mg} / \mathrm{L})$, while the TP concentration in industrial wastewater $(0.8 \mathrm{mg} / \mathrm{L})$ is around 4.5 times lower than that of the municipal wastewater $(3.5 \mathrm{mg} / \mathrm{L})$.Because of these different starting nutrient concentrations in industrial wastewater compared to the municipal one, we observed also different dynamics of $\mathrm{N}$ and $\mathrm{P}$ removal by duckweeds. While the major portion of $\mathrm{N}$ was consumed during the first 3 days from the municipal water, for industrial wastewater the similar high removal rate has been continued till day 7 (Figure 3(A)). Duckweed needed about 8 days to lower the TN concentration when growing in industrial wastewater to the starting $\mathrm{N}$ concentration in municipal wastewater $(20 \mathrm{mg} / \mathrm{L})$, and another two weeks to lower the TN concentration to 

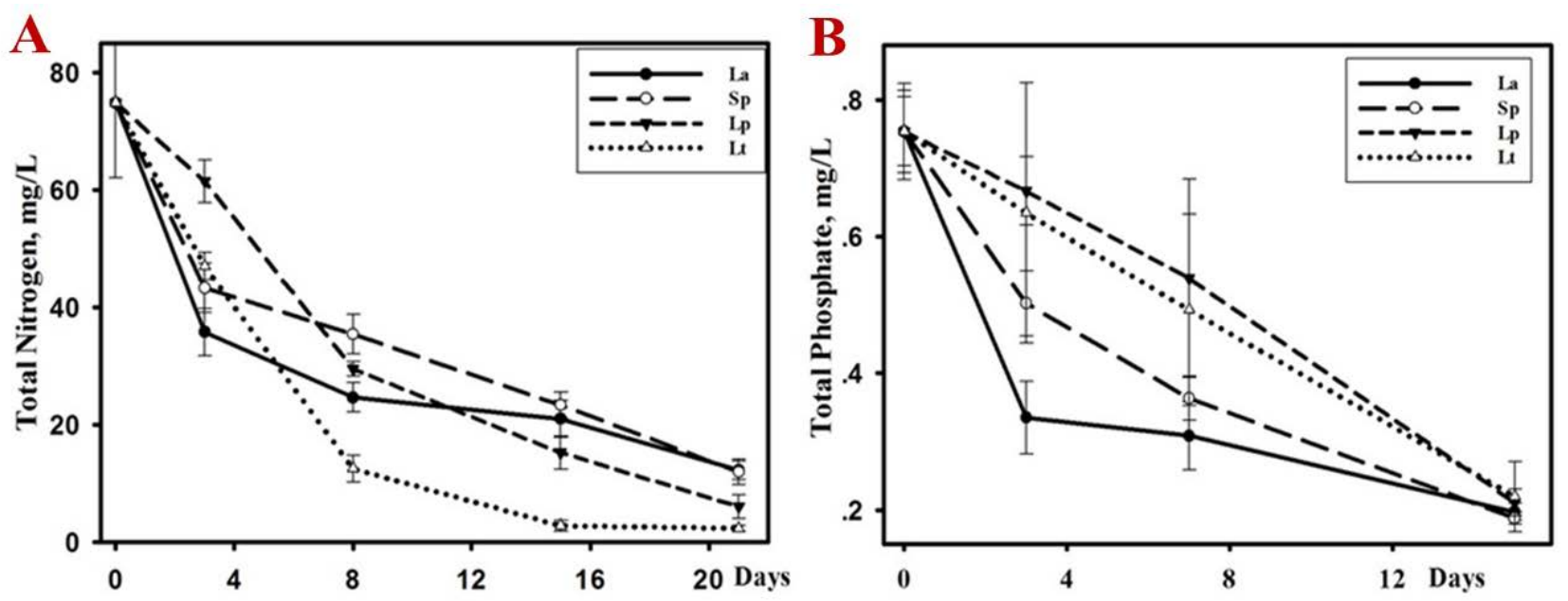

Figure 3. Removal of $\mathrm{N}(\mathrm{A})$ and $\mathrm{P}(\mathrm{B})$ removal from industrial wastewater by duckweeds. La: L. aequinoctialis; Sp: S. polyrhiza; Lp: L. punctata; Lt: L. turionefera.

the National standard for treated wastewater of $15 \mathrm{mg} / \mathrm{L}$.During 15 days, all duckweed species were able to lower the TP concentration down to around 0.2 $\mathrm{mg} / \mathrm{L}$ (Figure 3(B)).

\section{Discussion and Conclusions}

Duckweed is considered as a promising macrophyte for sustainable wastewater treatment due to their rapid growth, ease of harvesting and the potential of produced biomass use as organic fertilizers or a feedstock for producing biofuel and other products. The recent intensive studies of various duckweed species for wastewater remediation [15] have demonstrated the importance of duckweed ecotype selection best suited for the particular local remediation projects. In the presented work, we have collected samples of duckweed in eastern China (mainly from Hongze Lake in Jiangsu province and Shanghai), identified the species biodiversity by molecular markers and tested four selected ecotypes for bioremediation of local municipal and industrial wastewater. Molecular genotyping using two chloroplast DNA markers [12] revealed S. polyrhiza as the clear dominant duckweed species in all locations of the area. Other duckweeds grown in the area were identifies as $L$. punctata, $L$. aequinoctialis, $L$. turionifera and $W$. globosa. Isolates of $S$. polyrhiza, L. aequinoctialis, L. punctata and L. turionifera were selected for wastewater remediation. All tested duckweed species were quite efficient in removing $\mathrm{N}$ and $\mathrm{P}$ from the wastewater, however demonstrated different accumulation dynamics. L. punctata showed the slowest rate of $\mathrm{N}$ and $P$ removal during the first 3 days in the experiments with both municipal and industrial wastewater, while $L$. turionifera demonstrated fastest removal rate with the municipal wastewater (Figure 2) and L. aequinoctialis with the industrial wastewater (Figure 3).

By the end of the tests in 15 days, all duckweed species removed up to $98 \%$ of $\mathrm{N}$ and up to $96 \%$ of $\mathrm{P}$ from the municipal influent wastewater. After treating 
with duckweeds, the final TN concentration was reduced from 21 to $1 \mathrm{mg} / \mathrm{L}$ and TP concentration from 3.5 to $0.2 \mathrm{mg} / \mathrm{L}$. For industrial wastewater, with the starting TN concentration 3.5 fold higher compared to the municipal influent, the $\mathrm{N}$ removal rate was about $84 \%$ for $L$. aequinoctialis and $S$. polyrhiza, and 92\% for L. punctata and L. turionefera. Because the starting P concentration was low in industrial wastewater, the TP concentration was around $0.2 \mathrm{mg} / \mathrm{L}$, with the $\mathrm{P}$ removal rate between $70 \%-75 \%$.

In summary, our experimental data suggest that L. aequinoctialis and S. polyrhiza are preferred species for the treatment of local municipal wastewater with the moderate concentrations of $\mathrm{N}$ and $\mathrm{P}$, while L. punctata and L. turionefera are more efficient species for the remediation of local industrial wastewater with high $\mathrm{N}$ and low $\mathrm{P}$ concentrations.

\section{Acknowledgements}

This work was supported financially by Natural Science Foundation of Jiangsu Province (BK20131213), the Foundation (No. HSXT2-320) of Key Jiangsu Collaborative Innovation Center of Regional Modern Agriculture \& Environmental Protection and the Foundation (No.JSBEET1303) of Jiangsu Key Laboratory for Biomass-based Energy and Enzyme Technology.

\section{References}

[1] Priya, A., Avishek, K. and Pathak, G. (2001) Assessing the Potentials of Lemna Minor in the Treatment of Domestic Wastewater at Pilot scale. Environmental Monitoring and Assessment, 184, 4301-4307. https://doi.org/10.1007/s10661-011-2265-6

[2] Srivastava, J., Gupta, A. and Chandra, H. (2008) Managing Water Quality with Aquatic Macrophytes. Revised Environmental Science Biotechnology, 7, 255-266. https://doi.org/10.1007/s11157-008-9135-x

[3] Cao, L. and Wang, W. (2010) Wastewater Management in Freshwater Pond Aquaculture in China. In: Sumi, A., Fukushi, K., Honda, R. and Hassan, K.M., Eds., Sustainability in Food and Water. An Asian Perspective, 181-190.

[4] He, F. and Wu, Z. (2003) Application of Aquatic Plants in Sewage Treatment and Water Quality Improvement. Chinese Bull. Botany, 6, 641-647 [in Chinese].

[5] Conley, D.J., Paerl, H.W., Howarth, R.W., et al. (2009) Controlling Eutrophication by Reducing Both Nitrogen and Phosphorus. Science, 323, 1015-1016.

[6] Dhote, S. and Dixit, S. (2009) Water Quality Improvement through Macrophytes-A Review. Environmental Monitoring and Assessment, 152, 149-153. https://doi.org/10.1007/s10661-008-0303-9

[7] Xu, J. and Shen, G. (2011) Growing Duckweed in Swine Wastewater for Nutrient Recovery and Biomass Production. Bioresource Technology, 102, 848-853. https://doi.org/10.1016/j.biortech.2010.09.003

[8] Mkandawire, M. and Dudel, E.G. (2007) Are Lemna spp. Effective Phytoremediation agents? Bioremediation, Biodiversity and Bioavailability, 1, 56-71.

[9] Appenroth, K.J., Sree, K.S., Böhm, V., Hammann, S., Vetter, W., Leiterer, M. and Jahreis, G. (2017) Nutritional Value of Duckweeds (Lemnaceae) as Human Food. Food Chemistry, 217, 266-273. https://doi.org/10.1016/j.foodchem.2016.08.116 
[10] Soda, S., Ohchi, T., Piradee, J., Takai, Y. and Ike, M. (2015) Duckweed Biomass as a Renewable Biorefinery Feedstock: Ethanol and Succinate Production from Wolffia globose. Biomass Bioenergy, 813, 364-368.

https://doi.org/10.1016/j.biombioe.2015.07.020

[11] Chen, M., Liu, Z. and Bian, Z. (2002) Wastewater Purifying Technology of Intensive aquiculture Greenhouse: A Case Study on an Automatically Controlled Ecological Greenhouse. Agro-Engineering Transaction, 18, 95-97. [in Chinese]

[12] Borisjuk, N., Chu, P., Gutierrez, R., Zhang, H., Acosta, K., Friesen, N., Sree, S.K., Garcia, C., Appenroth, K.J. and Eric, L. (2015) Assessment, Validation and Deployment Strategy of A Two-Barcode Protocol for Facile Genotyping of Duckweed Species. Plant Biology, 1, 42-49. https://doi.org/10.1111/plb.12229

[13] Schenk, R.U. and Hildebrandt, A.C. (1972) Medium and Techniques for Induction and Growth of Monocotyledonous and Dicotyledonous Plant Cell Cultures. Canadian Journal of Botany, 50, 199-204. https://doi.org/10.1139/b72-026

[14] Appenroth, K.J., Borisjuk, N. and Lam, E. (2013) Telling Duckweed Apart: Genotyping Technologies for the Lemnaceae. Chinese Journal of Applied and Environmental Biology, 19, 1-10. https://doi.org/10.3724/SP.J.1145.2013.00001

[15] Ziegler, P., Sree, S. and Appenroth, K. (2016) Duckweeds for Water Remediation and Toxicity Testing. Toxicological \& Environmental Chemistry, 98, 1127-1154. https://doi.org/10.1080/02772248.2015.1094701 